\title{
Freeze-thaw damage analysis of concrete material for channel lining structure
}

\author{
Gong Yaqi ${ }^{1,2, a}$, Xie Zhiqiang ${ }^{1,2, b}$, Chen Qin ${ }^{1,2, c}$ \\ ${ }^{1}$ Department of Material and Structure, Changjiang River Scientific Research Institute, Wuhan, \\ 430010, China; \\ ${ }^{2}$ National Dam Safety Engineering Research Center, Wuhan 430010, China; \\ agongyq@mail.crsri.cn, ${ }^{b}$ Xiezhq@mail.crsri.cn, ${ }^{c}$ chenq@mail.crsri.cn
}

\begin{abstract}
Keywords: Concrete material; Freeze-thraw process; Damage analysis; Finite element method Abstract. Freeze-thaw damage is a common form of damage to concrete materials, especially in cold regions. The deterioration process of hydraulic concrete material of channel lining structure the under the freeze-thaw cycles is analyzed. The damage evolution equation is deduced and freeze-thaw zone is discussed. The results indicate that the deterioration of hydraulic concrete material under the freeze-thaw cycles occurs mostly in the region of water fluctuation district, which is the freeze-thaw zone. The load capacity of structure after freeze-thaw process is also degraded major in the freeze-thaw zone and has little effect to the other section. This means that the damage of the freezing-thawing process in the coldest region will cause the local failure. The local protection in the freeze-thaw zone region is mostly important to concrete material in cold regions.
\end{abstract}

\section{Introduction}

Deterioration of concrete caused by frost action (freeze-thaw cycles) is a significance issue with regard to the service life of concrete structures in cold climates. The freeze-thaw resistance is an important measure in hydraulic concrete durability research. In cold region, especially the West China, concrete performance deterioration caused by freeze-thaw cycles has seriously affected the function of structure as well as the long-term safety. The mechanism of freeze and thaw damage has been investigated for several decades. Powers [1-2] indicated that the harmful stresses could result from hydraulic pressure created by the volume increase when water transforms into ice. It has been established that water-saturated porous media exposed to frequent frost first expand and then are damaged by the repetition of freezing and thawing cycles [3]. Damage can be caused by local stresses from the expansion of ice crystals (9\% expansion of water upon freezing) and internal pressures induced by the transfer of liquid water [4]. Scherer argued that the primary source of stresses during freezing should be the crystallization pressure of ice, but not hydraulic pressure [5]. Mei [6] established an empirical formula between mechanical parameter of concrete and freeze-thaw cycles basing on the test results, and then simulated the concrete damage process and the stress and strain of a water pier in freeze-thaw cycling condition.

In the present paper, the deterioration process of hydraulic concrete under freeze-thaw cycling condition is to be simulated, based on the theory of damage finite element method. A dam damage failure under freeze-thaw cycle in Tibet of China is analyzed.

\section{Formulation of models}

The follows should be considered in the damage analysis of freeze-thaw cycles. One is the deduction of damage evolution equation; the other is definition of freeze-thaw zone. 


\section{Damage evolution equation}

Generally, it believes that concrete damage is anisotropic during the freezing process. Unfortunately, the anisotropic damage evolution equation is difficult to draw. In most cases, freeze-thaw damage is simplified to be isotropic damage and the damage variable $\mathrm{D}$ is a scalar.

Under the strain equivalence hypothesis, the damage variable can be expressed as

$$
D=1-\sqrt{\frac{E}{E^{O}}}
$$

where $E$ is elastic modulus before damage and $E^{\prime}$ is elastic modulus after damage.

Currently the damage evolution equation is widely used as sub-linear expressions, sub-curve expression, bilinear expressions, parabolic expression, and power function expression. The damage evolution equation deduced by Mei [6] is adopted in this paper.

\section{Freeze-thaw zone}

Many research works have found out that the freeze-thaw damage is a local failing process. Currently, Zhang [7] carries out a field test in an irrigation cannel with concrete lining. The cannel is nearly $500 \mathrm{~m}$ long. Freeze-thaw observation is divided into two parts: cannel contains shallow water (water depth of $10 \mathrm{~cm}-5 \mathrm{~cm}$ ) and deep water (water depth of $50 \mathrm{~cm}-60 \mathrm{~cm}$ ) in winter. After a run-time term of winter, the concrete linings are almost damaged at the areas of water fluctuation district either within shallow water or deep water.

The site observation discovered that freeze-thaw damage occurred in the region of water fluctuation district mostly. This assumption is adopted in the present paper.

\section{Results and discussion}

In this study, a concrete material of trapezoidal channel lining structure in XinJiang region is analyzed to validate the proposed method. The channel locates in the southern margin of Junggar Basin, the east of which is Manas River and west is Bayin River. Its geographic position is $85^{\circ} 00^{\prime} \sim 86^{\circ} 30^{\prime}$ east longitude and $43^{\circ} 27^{\prime} \sim 45^{\circ} 20^{\prime}$ north latitude, most area of which features a huge temperature difference between days and nights. Freeze-thaw damages are widely surveyed for the concrete structure.

The cross section of channel is a bilateral symmetrical trapezoidal. The bottom width is 2 meter and top width is 10.75 meter. The depth is 2.5 meter and the cross slope is 1 in 1.75 . The thickness of lining is 1 meter.

The two-dimensional plane strain finite element model is shown in Fig.1. The foundation is extended 2.5 times higher than the channel depth in depth direction, and 2 times width in left and right direction. The bottom of foundation is totally restrained and the both sides are horizontal constrained. The model includes 6388 elements and 6613 nodes. The water depth is 2 meter and the depth of water fluctuation district is $0.5 \mathrm{~m}$, where the elements are refined as shown in Fig. 1 in order to reflect the deterioration of material and mechanical properties. 


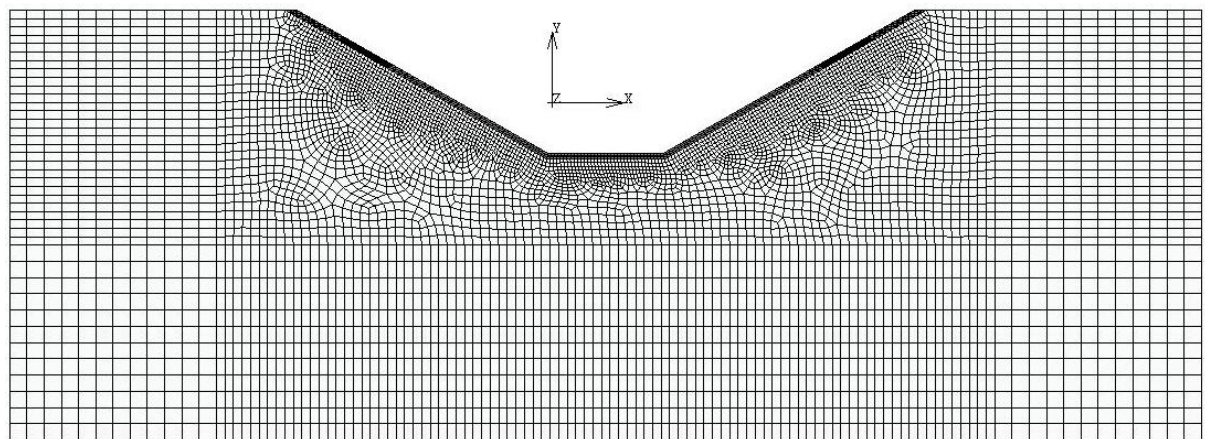

Fig.1 Finite element model of channel concret lining struture

Table 1 Mechanical parameter of concrete under different freeze-thaw cycles [6]

\begin{tabular}{cccc}
\hline Freeze-thaw cycles & 0 & 25 & 50 \\
\hline Young' s Modulus [GPa] & 27.72 & 24.89 & 17.79 \\
Poisson's ratio & 0.167 & 0.167 & 0.167 \\
Bulk density [kN/m $]$ & 24.00 & 23.99 & 23.90 \\
Uniaxial tensil tensile strength [MPa] & 1.91 & 1.39 & 1.01 \\
Uniaxial Compression tensile strength [Mpa] & 13.8 & 10.05 & 7.31 \\
\hline
\end{tabular}

Table 1 lists the mechanical parameters of concrete under the different freeze-thaw cycles according to the test [6]. From which we can see that the Young's modulus degrades to $35.8 \%$ under 50 freeze-thaw cycles, but Poisson's ratio and Bulk density remains unchanged.

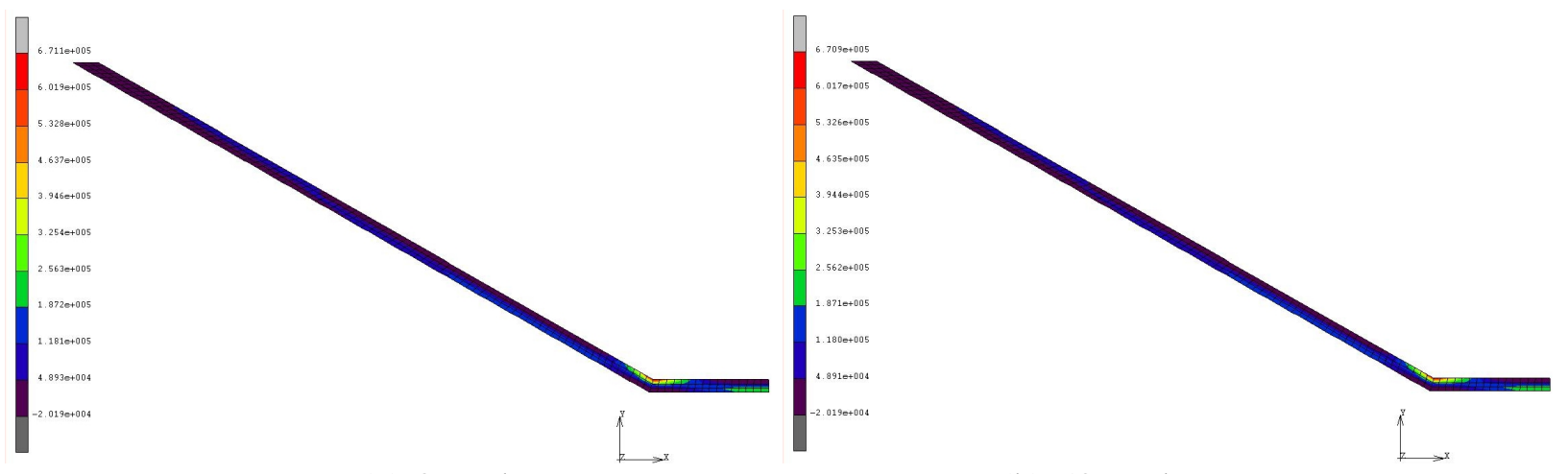

(a) 0 cycles

(b) 50 cycles

Fig.2 Principal stress distribution of half mode under different freeze-thaw cycles [m]

Fig.2 demonstrates the first principal stress of concrete lining under different freeze-thaw cycles. After 50 freeze-thaw cycles under the same loads, the stress has little change in the whole structure. The most change is located in the freeze-thaw zone as shown in Fig.3. 

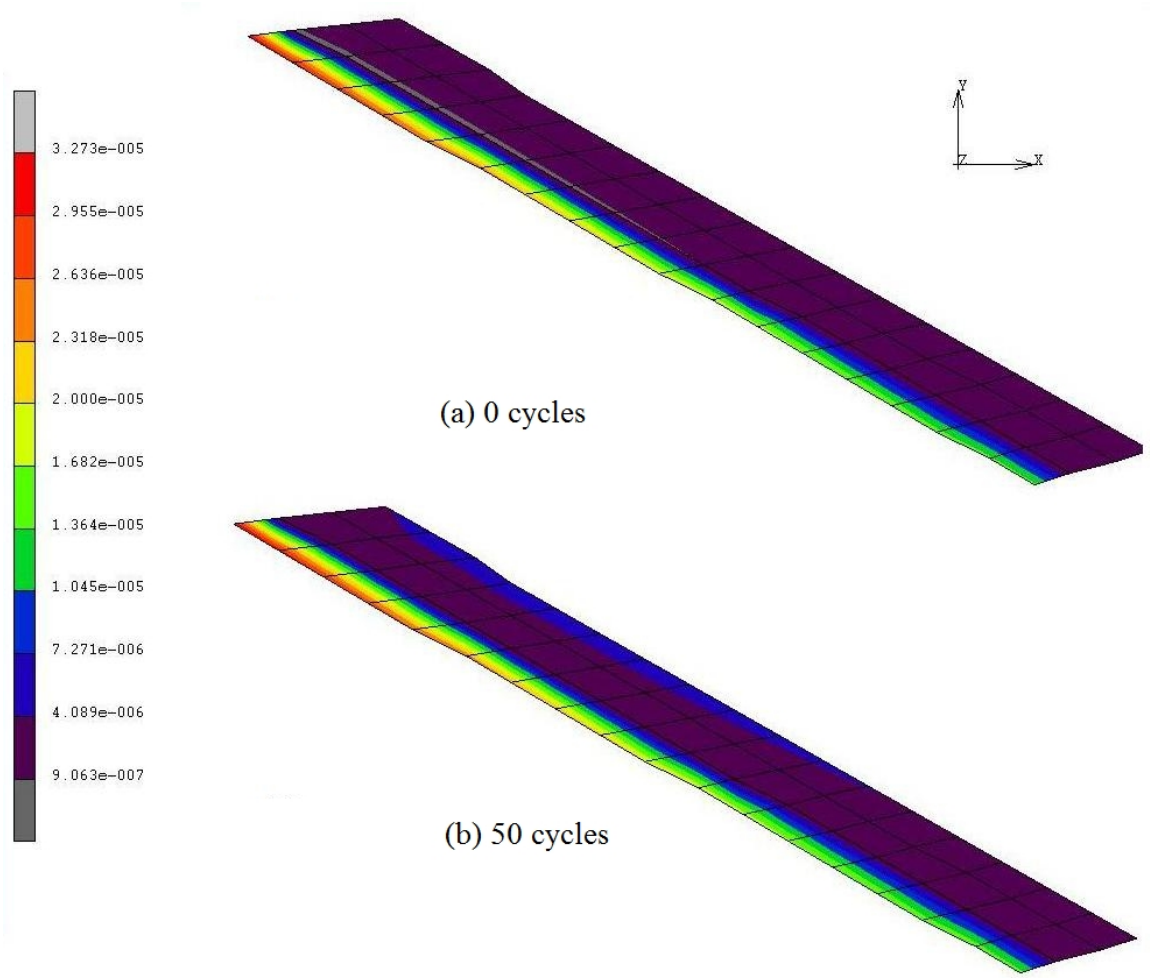

Fig.3 The principle strain at the freeze-thaw zone under different freeze-thaw cycles [Pa]

Fig. 3 illustrates the principle stress at the freeze-thaw zone under different freeze-thaw cycles. In order to compare clearly, the principle stress distributions under 0 freeze-thaw cycles and 50 freeze-thaw cycles are combined together into one picture and the legends are set to the same scale. From the picture, we can see that the magnitude of principle stress under 50 freeze-thaw cycles at the area of freeze-thaw zone is smaller than that under no freeze-thaw cycles, which means that the load capacity of concrete decreasing with the increasing of freeze-thaw cycle. The maximum stress decreases from $0.108 \mathrm{MPa}$ before freezing and thawing to $0.094 \mathrm{MPa}$ after freezing and thawing. In the range of freezing and thawing, with the increase of freezing and thawing cycles, and the range of strain change in the freeze-thaw zone also increases.

\section{Conclusions}

The freeze-thaw process is modeled based on the theory of damage finite element method. The results indicate that freeze-thaw cycles process a significant defection in the stress and strain of the freeze-thaw zones, but it causes a little effect on the overall structure if only general loads applied, such as gravity load and water pressure load are applied. While from the whole perspective, the effect of freeze-thaw is limited mainly in the region of water fluctuation district area. That is to say the freeze-thaw damage is a local failure problem in respect to the whole hydraulic structure.

This indicates that the major loads cause hydraulic concrete failure in the coldest region is not those of general design loads, but the thermal loads. Climate information denotes that extreme temperature on North and West China can almost cause the daily temperature difference between $20^{\circ} \mathrm{C}$ to $30^{\circ} \mathrm{C}$. The deterioration of concrete material caused by freeze-thaw cycles affects the safety of structure seriously. Therefore, the local protection in the freeze-thaw zone region is mostly important to concrete material in such cold regions.

\section{Acknowledgements}

This work was financially supported by the Fundamental Research Funds for Central Public Welfare Research Institutes (CKSF2015033/CL, CKSF2016022/CL, CKSF2017040/CL) and National Natural Science Foundation of China (51409012). 


\section{References}

[1] T.C. Powers: Proc Highway Res Board Vol. 29 (1949), p. 184-211

[2] T.C. Powers, R.A. Helmuth: Proc Highway Res Board (1953)

[3] V. Penttala: Adv Cem Based Mater Vol. 7 (1998), p. 8-19

[4] G.W. Scherer GW: Cem Concr Res Vol. 29 (1999), p. 1347-1358

[5] G.W. Scherer GW, J.J. Valenza, in: Mechanisms of Frost Damage, Materials Science of Concrete VII, edtied by F. Young and J. Skalny/American Ceramic Society (2005)

[6] Mingrong Mei, Xiaomin Yu, Shanshan Wang, Qingwen Ren: Journal of Hydroelectric Engineering Vol. 29 (2010), p. 102-105 (in Chinese)

[7] Linying Zhang: Water Resources Development and Management Vol. 2 (2010), p. 58-60 (in Chinese) 